\title{
Phosphorus in the Sediments of Yangzong Lake, China
}

\author{
Yuxi Zhang*(**), Bing Zhou*(**)† and Jiansheng Shi* \\ *The Institute of Hydrogeology and Environmental Geology, C.A.G.S., Shijiazhuang, China \\ $* *$ China University of Geosciences, Beijing, China \\ †Corresponding author: Bing Zhou; winnerg0126@ sina.com
}

\section{Nat. Env. \& Poll. Tech. \\ Website: www.neptjournal.com \\ Received: 17-10-2019 \\ Revised: 15-11-2019 \\ Accepted: 11-12-2019 \\ Key Words: \\ Phosphorus \\ Sediments \\ Yangzong lake \\ Distribution characteristics \\ Influencing factors}

\begin{abstract}
Total 150 sediments samples were collected from the Yangzong Lake, and the total phosphorus, $\mathrm{pH}$, redox potential and organic carbon were analysed to quantitatively study the dispersal and sources of phosphorus and its influential factors. The results indicated that the total phosphorus content in sediments was $318-3931 \mathrm{mg} / \mathrm{kg}$, which decreased slightly with depth. In the sediments at the depths of $0-2 \mathrm{~cm}, 2-4 \mathrm{~cm}, 4-6 \mathrm{~cm}, 6-8 \mathrm{~cm}$ and $8-10 \mathrm{~cm}$, the phosphorus contents were $1151 \mathrm{mg} / \mathrm{kg}, 1126 \mathrm{mg} / \mathrm{kg}$, $1138 \mathrm{mg} / \mathrm{kg}, 1057 \mathrm{mg} / \mathrm{kg}$ and $893 \mathrm{mg} / \mathrm{kg}$ respectively. The contents of phosphorus in the sediments were high on both north and south banks and reduced gradually towards the centre of the lake. Before the 1980s, the phosphorus distribution in the sediments was mainly influenced by natural factors such as $\mathrm{pH}$ value, redox potential and organic matter. But after the 1980s, the phosphorus distribution was mainly affected by the position of sewage discharge. Sources of phosphorus in the sediments have changed from the local source to the multiple sources, and from the point source to surface source. Currently, soil erosion and agricultural non-point source pollution are the main sources of phosphorus in Yangzong Lake.
\end{abstract}

\section{INTRODUCTION}

As one of the main nutrients in a lake ecosystem, phosphorus has a very important effect on the lake eutrophication (Liu et al. 2012, Luo et al. 2017, Lü et al. 2018). As one of the nine plateau lakes in Yunnan Province, Yangzong Lake is the freshwater lake for local residents (Zhang et al. 2010). With the rapid development of industry and agriculture around the Yangzong Lake and continuous input of exogenous nutrients, the eutrophication problem of the Yangzong Lake has become increasingly prominent. The sudden "water bloom" incidents occur from time to time (Zhang et al. 2013). In recent years, the water body itself is usually taken as the object in the eutrophication study of the Yangzong Lake. However, the study on the distribution of phosphorus in the sediment is seldom reported. The phosphorus stored in the sediments is a potential source of endogenous pollution for the overlying water. It can be released from sediments into the water under appropriate conditions.

Through the high-density stratified sampling for the sediments in the Yangzong Lake, the distribution characteristics of phosphorus in the sediments and its influence factors were investigated. The source and pollution history of phosphorus were discussed. The work provides a scientific basis for the accurate evaluation and improvement of the environmental quality and also for the pollution control and protection of Yangzong Lake.

\section{MATERIALS AND METHODS}

\section{Study Area}

Yangzong Lake (E102 $\left.59^{\prime}-103^{\circ} 02^{\prime}, \mathrm{N} 24^{\circ} 51^{\prime}-24^{\circ} 58^{\prime}\right)$ belongs to Nanpan River system of the Pearl River Basin. The lake surface is in fusiform shape, with the width of $2.5 \mathrm{~km}$ from west to east and the length of $12.7 \mathrm{~km}$ from north to south. The shoreline is $32.3 \mathrm{~km}$ long. The lake has the drainage area of $286 \mathrm{~km}^{2}$ and the lake surface area of $31.9 \mathrm{~km}^{2}$ (at the water level of $1770 \mathrm{~m}$ ). The maximum depth is $29.1 \mathrm{~m}$, and the water storage capacity is 0.604 billion $\mathrm{m}^{3}$. The water exchange cycle is 13a (Zhang et al. 2012). The recharge water sources are mainly natural rainfall, the catchment of the Yangzong Lake and the Qixing Lake, the artificial recharge from Baiyi River, and groundwater. The lake water empties into the Nanpan River through the only water outlet, Tangchi River.

\section{Sampling and Analysis}

The sediments of the Yangzong Lake were systematically sampled, as shown in Fig. 1. To obtain the distribution characteristics of phosphorus in the sediments from the Yangzong Lake, seven cross-sections were arranged from south to north at the interval of about $1.5 \mathrm{~km}$. The sampling points were set up on the eastern and western banks of each cross-section and at the centre of the lake. The sampling points were more 
densely arranged in the water areas near the industrial and mining enterprises around the lake. A total of 30 sampling points were set and numbered N01-N30. The collection and stratification of samples were performed using the "LENZ sediment sampler" manufactured by HYDRO-BIOS (Germany). The sampling was done at every $2 \mathrm{~cm}$ from top to bottom for each sampling point. There were five layers in total. Finally, a total of 150 samples were obtained. The samples were put into polyethylene bags and the bags were sealed.

The sediment samples were air-dried in the laboratory. After the removal of plant and animal residues and stones, the samples were ground and passed through the nylon screen (200 mesh). After the bottling, the samples were sent to the Geochemical Exploration Supervision and Testing Center of the Ministry of Land and Resources. The testing indicators included total phosphorus, $\mathrm{pH}$ value, redox potential and total organic carbon. The analytical methods included plasma spectroscopy (ICP-OES) and potential method. The soil reference materials conforming to the national standard (GSF-2, GSF-3, GSF-4) and repeated samples were added for quality control in the analysis process. The qualification rates of the reference materials and repeated samples were all $100 \%$. The result of the experiment was reliable. The data were analysed by Microsoft Excel 2003 and SPSS18. 0 . The diagram was drawn using Mapgis6.7. The isoline was interpolated by Universal Kriging method.

\section{RESULTS AND DISCUSSION}

\section{Phosphorus Content}

The contents of phosphorus in the sediments from the Yangzong Lake were mostly above the lower limit of concentration $(600 \mathrm{mg} / \mathrm{kg})$ that could cause ecological toxicity in the guideline issued by the Ontario Ministry of Energy, Canada (1992) (Sieliechi et al. 2014). This indicates the potential ecological risk.

The content of phosphorus in the sediments of the surface layer $(0-2 \mathrm{~cm})$ was in the range of $836-1910 \mathrm{mg} / \mathrm{kg}$. The average value was $1151 \mathrm{mg} / \mathrm{kg}$. The contents of phosphorus in the sediments on the north and south banks were high and

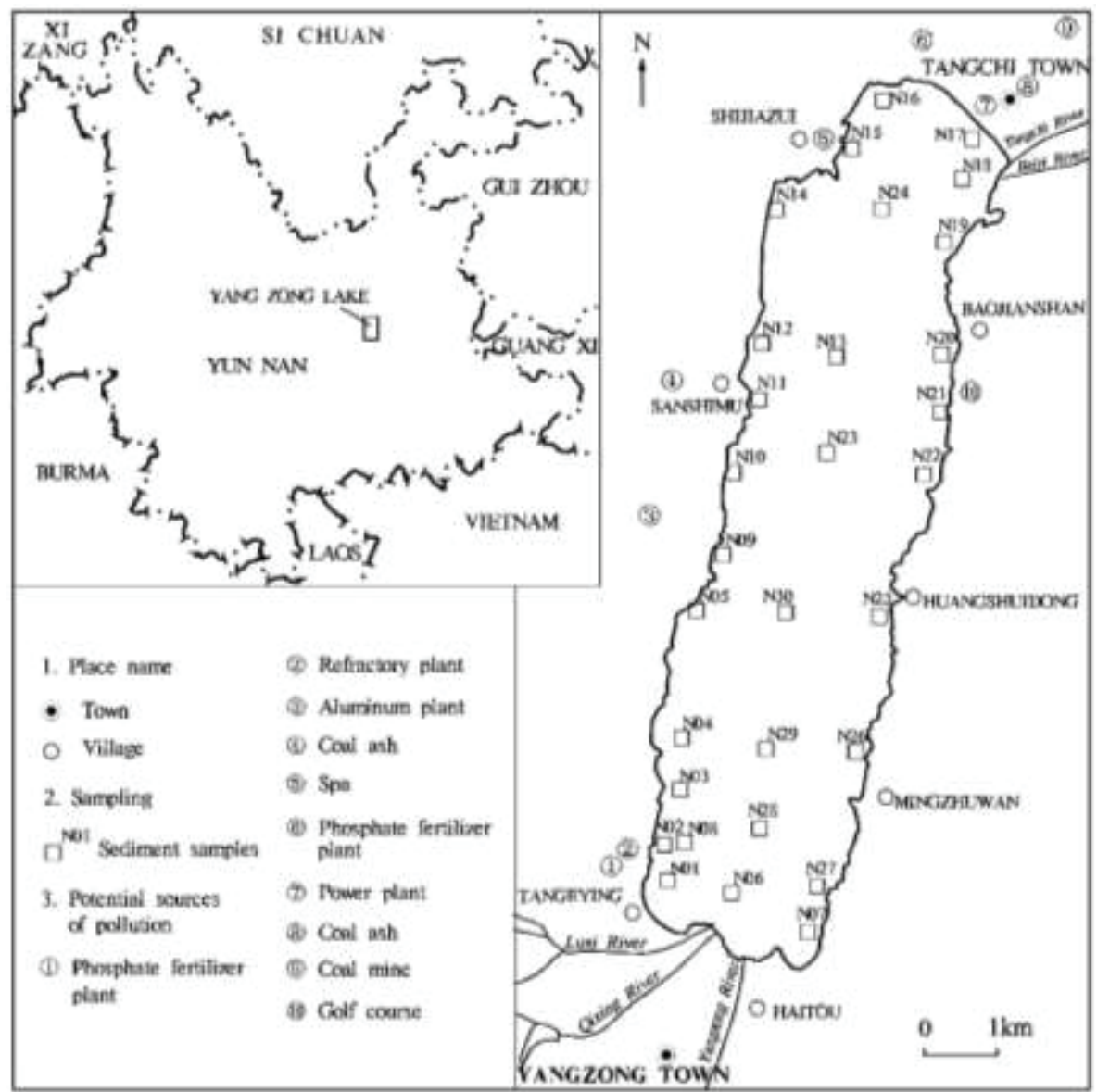

Fig. 1: Sampling sites in Yangzong Lake. 
generally above $1400 \mathrm{mg} / \mathrm{kg}$. The point N16 on the north bank had the highest value. The contents of phosphorus in the middle of the lake were relatively low. Most of them were below $1000 \mathrm{mg} / \mathrm{kg}$, with the minimum value occurring at the point $\mathrm{N} 30$.

The content of phosphorus from the depth of $2-4 \mathrm{~cm}$ was $685-2346 \mathrm{mg} / \mathrm{kg}$. The average value was $1126 \mathrm{mg} / \mathrm{kg}$. The regional distribution of phosphorus at this depth showed more significant variation than that of the surface layer. The contents of phosphorus on the north bank and the southeast corner were high. They were generally above $1400 \mathrm{mg} / \mathrm{kg}$. The point $\mathrm{N} 27$ at the southeast corner had the maximum value. The contents of phosphorus in the middle of the lake area were low. The contents in part of the western lake were less than $800 \mathrm{mg} / \mathrm{kg}$. The point N10 on the west bank had the minimum value.

The contents of phosphorus in the sediments from the thickness of $4-6 \mathrm{~cm}$ were in the range of $547-3931 \mathrm{mg} / \mathrm{kg}$. The average was $1138 \mathrm{mg} / \mathrm{kg}$. The variation in regional distribution of phosphorus was more significant. The areas with high contents of phosphorus were the north bank and southeast corner. The contents of phosphorus on the north bank changed little compared with that in the upper layer. However, the phosphorus content in the southeast corner significantly increased compared with that in the upper layer. The point N27 had the highest value, which was also the maximum content of phosphorus in the sediments of the entire Yangzong Lake. The contents of phosphorus in the middle of the lake were still low. Larger areas near the west and east banks had the contents of phosphorus less than $800 \mathrm{mg} / \mathrm{kg}$ compared with the upper layer.

The contents of phosphorus in the sediments from the depth of $6-8 \mathrm{~cm}$ ranged from 475 to $2460 \mathrm{mg} / \mathrm{kg}$. The average was $1057 \mathrm{mg} / \mathrm{kg}$. The areas with a high content of phosphorus were on the north and south banks. The content of phosphorus in the north bank was higher compared with that in the upper layer. The content in the southeast corner significantly decreased compared with that in the upper layer. The point N27 still had the maximum value. The content of phosphorus in the middle of the lake decreased, and those in part of west and east banks were less than $600 \mathrm{mg} / \mathrm{kg}$. The point $\mathrm{N} 21$ on the east bank had the minimum value. The content of phosphorus in the sediments from the depth of $8-10 \mathrm{~cm}$ was $318-1734 \mathrm{mg} / \mathrm{kg}$. The average was $893 \mathrm{mg} / \mathrm{kg}$.

The contents of phosphorus in the whole lake area decreased significantly. The areas with phosphorus content larger than $1400 \mathrm{mg} / \mathrm{kg}$ were shrunken sharply on the north bank. They disappeared on the south bank. The content of phosphorus was above $1000 \mathrm{mg} / \mathrm{kg}$ only in part of the southeast corner. The point N17 on the north bank had the maximum value. There was an enlargement of the area with the phosphorus content less than $600 \mathrm{mg} / \mathrm{kg}$ in the middle of the lake. The contents of phosphorus in part of the east bank were less than $400 \mathrm{mg} / \mathrm{kg}$. The point N20 on the east bank had the minimum value.

The spatial distribution of phosphorus in different layers of sediments is shown in Fig. 2. The general distribution pattern was that the contents of phosphorus are high on the

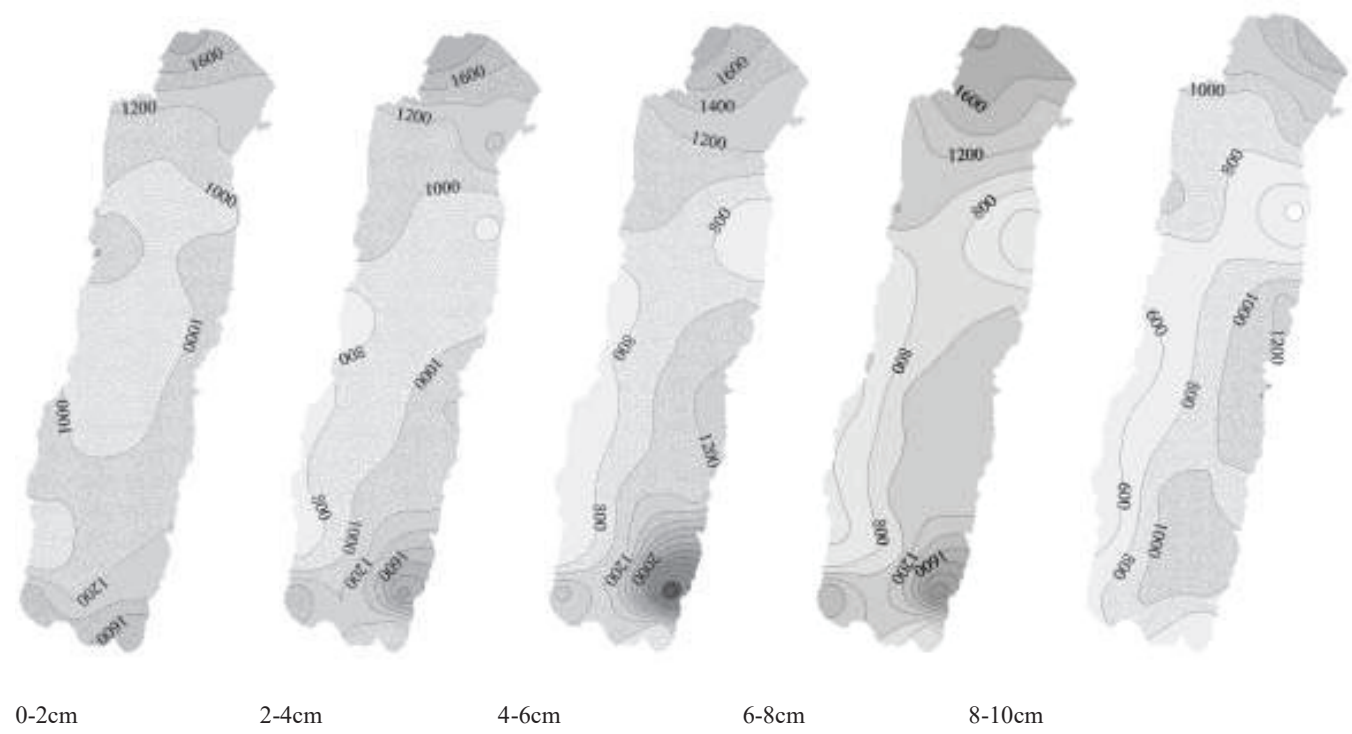

Fig. 2: Spatial distribution of phosphorus in sediments of Yangzonghai Lake (mg/kg). 
north and south banks. The content of phosphorus decreased gradually towards the centre of the lake. There were three regions with high contents of phosphorus, near Tangchi on the north bank, in the south of the Pearl Bay in the southeast corner, and near Tangeying in the southwest corner. The low phosphorus contents were mainly found in two areas, along the shore from Tangeying on the west bank to Sanshimu and the near Baojianshan District on the east bank.

Vertically, the contents of phosphorus in the sediments presented a decreasing trend from top to bottom layers of the sediments, as shown in Fig. 3. The contents of phosphorus in the sediments from the depth of $0-6 \mathrm{~cm}$ decreased slowly, and those below $6 \mathrm{~cm}$ decreased significantly. The contents of phosphorus were high on the north and south banks. The contents of phosphorus in the sediments increased first and then decreased from top to bottom. The content of phosphorus in the sediments from the depth of 4-6cm was the maximum in the south of the Pearl Bay. The phosphorus content in the sediments from the depth of $6-8 \mathrm{~cm}$ was the highest near Tangchi Town on the north bank.

\section{Analysis of Influencing Factors on Phosphorus}

The sediment adsorption on phosphorus is affected by many factors. The correlation analysis was performed for the four factors, i.e. phosphorus content in the sediments of each layer, $\mathrm{pH}$ value, redox potential and organic carbon (Table 1). The results indicated that the contents of phosphorus in the sediments of the upper layers $(0-4 \mathrm{~cm})$ were not related to any of these indices. However, the contents for the lower layers $(4-10 \mathrm{~cm})$ had a significant correlation with all indices. The sedimentation rate of the Yangzong Lake is about $1.55 \mathrm{~mm} / \mathrm{a}$. The sediments from the depth of $0-10 \mathrm{~cm}$ reflect the sedimen-

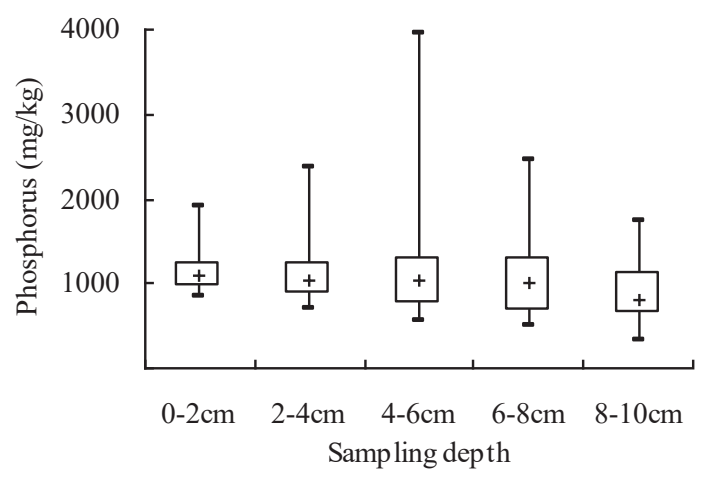

Fig. 3: Phosphorus content in sediments.

Table 1: Correlation between phosphorus content and $\mathrm{pH}, \mathrm{ORP}, \mathrm{OC}$ in sediment by various layers.

\begin{tabular}{|c|c|c|c|}
\hline Sampling layers & Regression Equation & $\mathrm{R}^{2}$ & $\mathrm{P}$ \\
\hline \multirow{3}{*}{$0-2 \mathrm{~cm}$} & {$[\mathrm{P}]=2.2365[\mathrm{pH}]+1133.6$} & $1 \times 10^{-7}$ & 0.988 \\
\hline & {$[\mathrm{P}]=-0.0378[\mathrm{ORP}]+1149.1$} & $1 \times 10^{-7}$ & 0.998 \\
\hline & {$[\mathrm{P}]=150.34[\mathrm{OC}]+619.48$} & 0.130 & 0.050 \\
\hline \multirow{3}{*}{$2-4 \mathrm{~cm}$} & {$[\mathrm{P}]=-1958.3[\mathrm{pH}]+16329$} & 0.066 & 0.155 \\
\hline & {$[\mathrm{P}]=33.102[\mathrm{ORP}]+2749.8$} & 0.064 & 0.146 \\
\hline & {$[\mathrm{P}]=191.97[\mathrm{OC}]+632.96$} & 0.211 & 0.015 \\
\hline \multirow{3}{*}{$4-6 \mathrm{~cm}$} & {$[\mathrm{P}]=-5845.4[\mathrm{pH}]+46277$} & 0.376 & 0.000 \\
\hline & {$[\mathrm{P}]=98.807[\mathrm{ORP}]+5743.3$} & 0.374 & 0.000 \\
\hline & {$[\mathrm{P}]=163.8[\mathrm{OC}]+779.27$} & 0.108 & 0.074 \\
\hline \multirow{3}{*}{$6-8 \mathrm{~cm}$} & {$[\mathrm{P}]=-3594.5[\mathrm{pH}]+28781$} & 0.240 & 0.005 \\
\hline & {$[\mathrm{P}]=60.624[\mathrm{ORP}]+3852.3$} & 0.238 & 0.006 \\
\hline & {$[\mathrm{P}]=190.19[\mathrm{OC}]+653.27$} & 0.325 & 0.001 \\
\hline \multirow{3}{*}{$8-10 \mathrm{~cm}$} & {$[\mathrm{P}]=-2362[\mathrm{pH}]+19082$} & 0.288 & 0.003 \\
\hline & {$[\mathrm{P}]=39.925[\mathrm{ORP}]+2703.8$} & 0.279 & 0.002 \\
\hline & {$[\mathrm{P}]=136.9[\mathrm{OC}]+631.03$} & 0.433 & 0.000 \\
\hline
\end{tabular}


tary environment since the 1960s. The contents of phosphorus in the sediments from the Yangzong Lake were generally low in the 1960s. There were very few human interventions at that time. The distribution was mainly affected by natural factors, such as $\mathrm{pH}$ value, redox potential and organic matter. Over time, human activities have been increased. In the last 20 years, with the rise of the agriculture, fisheries, mining and tourist industries near the Yangzong Lake, the pollutant emissions have been rising. The control effects of natural factors on the phosphorus distribution are masked by large, concentrated inputs. The position of pollutant emissions has gradually become the dominant factor for the phosphorous distribution in the sediments. The correlation of phosphorus in the sediments from the bottom to the top layers (from old to new) with each index decreased gradually. The area with a high content of phosphorus coincided with the area of intensive human activities.

pH: The $\mathrm{pH}$ value is the key factor that affects the sediment adsorption on phosphorus. Both high and low $\mathrm{pH}$ values can promote the release of phosphorus in sediments to the water body of the upper layer (Zhu \& Yang 2018). The sediment adsorption on phosphorus could be characterized with a " - shaped" curve with the increase of $\mathrm{pH}$ value. The study shows that the sediment adsorption on phosphorus is relatively low in the strongly acidic environment with $\mathrm{pH}<$ 2 . The adsorption quantity presents an increasing trend with the increase of $\mathrm{pH}$ value. The adsorption reaches the maximum near the neutral $\mathrm{pH}$ value. The sediment adsorption on phosphorus decreases with the increase of $\mathrm{pH}$ value in the alkaline environment with $\mathrm{pH}>7$ ( $\mathrm{Zhu}$ et al. 2012). This is because when the $\mathrm{pH}$ value is low, the concentration of $\mathrm{H}^{+}$ in water is high. It is easy for $\mathrm{H}^{+}$to bind to the phosphorous ion charged negatively in water, which results in the great reduction of the sediment adsorption on phosphorus. When

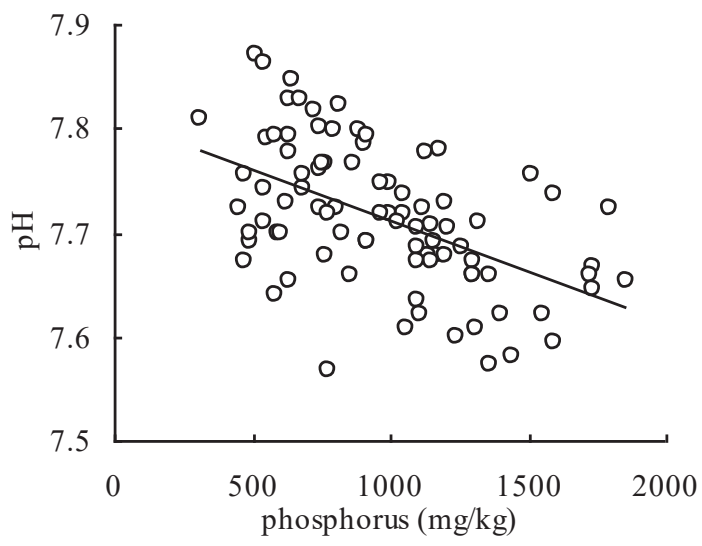

Fig. 4: Concentration of phosphorus as a function of $\mathrm{pH}$ in 4-10 cm sediments. the $\mathrm{pH}$ value is high, there are more $\mathrm{OH}^{-}$ions in water. They will compete for the adsorption points on the surface of sediments with the phosphorous ions in water. Therefore, the sediment adsorption on phosphorus will reduce. Only when the $\mathrm{pH}$ value is close to neutrality, the surface of sediments carrying positive charge will have an ability to compete for the phosphorous ions with the $\mathrm{H}^{+}$of low concentration. Meanwhile, the concentration of $\mathrm{OH}^{-}$is not too high. The phosphorus can compete with $\mathrm{OH}^{-}$to be adsorbed on the sediment surface. Therefore, the adsorption quantity of phosphorus will be higher ( $\mathrm{Li}$ et al. 2010).

The $\mathrm{pH}$ values of the sediments in the Yangzong Lake ranged from 7.53 to 7.94. The average $\mathrm{pH}$ values for each layer from top to bottom were 7.75, 7.72, 7.76, 7.71 and 7.70 , respectively. The $\mathrm{pH}$ values of sediments in each layer showed a small variation. The sediments were all weakly alkaline. The $\mathrm{pH}$ values of sediments from the depth of $4-10 \mathrm{~cm}$ had a very significant negative correlation with phosphorus content (Fig. 4), that is, the contents of phosphorus decreased with the increase of $\mathrm{pH}$ value.

ORP: Redox potential is one of the important parameters showing the adsorption of phosphorus onto the surface of oxides of $\mathrm{Fe}$ (hydrate), etc. (Koskiaho et al. 2015). When the sediments are in the oxidative environment, $\mathrm{Fe}^{3+}$ ions will bind to phosphorous ions and deposits in the sediments in the form of iron phosphate or the soluble phosphorus in water is adsorbed by ferric hydroxide, and gradually deposits. Meanwhile, the sediments have strong adsorption action on phosphorus. There will be no release of phosphorus. When the sedimentary environment is in the reducing state, the $\mathrm{Fe}^{3+}$ ions are reduced to $\mathrm{Fe}^{2+}$. The insoluble ferric hydroxide is changed into soluble ferrous hydroxide, which results in the release of phosphorus from the sediments into the water. The phosphorus concentration of the water body will

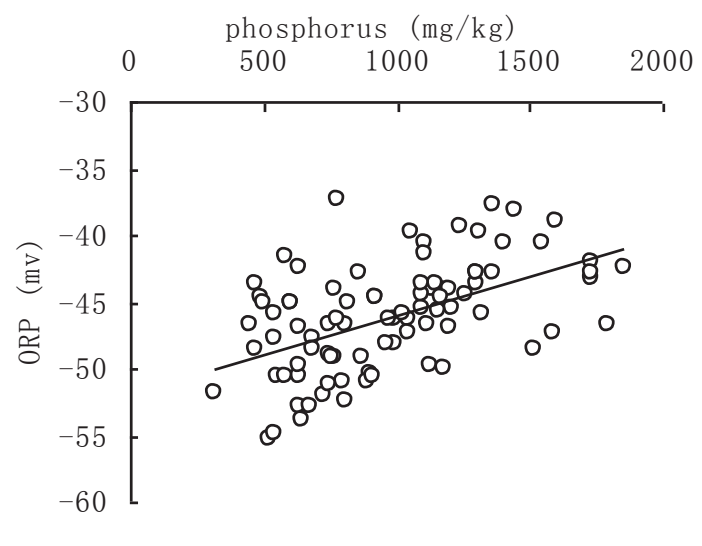

Fig. 5: Concentration of phosphorus as a function of ORP in $4-10 \mathrm{~cm}$ sediments. 


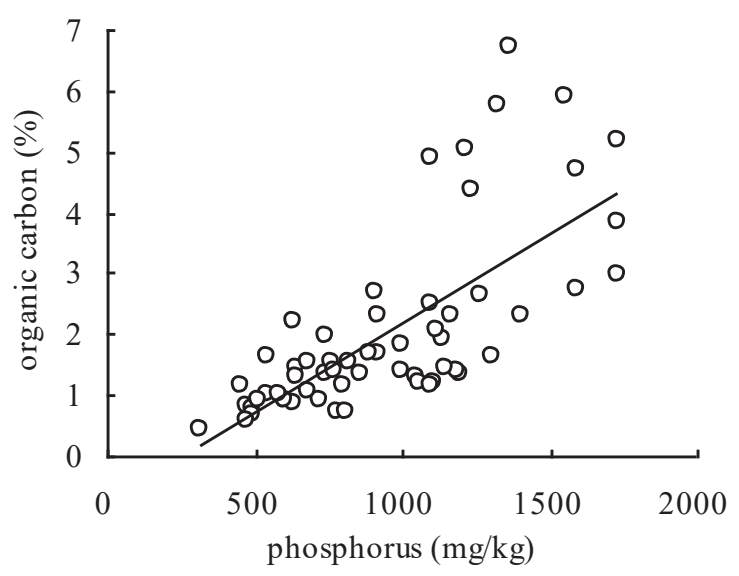

Fig. 6: Concentration of phosphorus as a function of OC in 6-10 cm sediments.

rise as a result. It was found through the continuous flow release system by Peng \& Chen (1987) that the release rate of phosphorus from the lacustrine sediments under reducing conditions was more than ten times larger than that under oxidizing conditions.

The redox potential of sediments in the Yangzong Lake ranged from -59 to -35 . The redox potentials of sediments in each layer showed a small variation. The sediments were all in the micro reducing environment. In this study, the redox potential of sediments from the depth of $4-10 \mathrm{~cm}$ had a significant positive correlation with total phosphorus in the sediments (Fig. 5). The content of phosphorus increased with the rise of redox potential.

Organic matter: Organic matter can promote the sediment adsorption on phosphorus as well as its deposition (Liu et al. 2016). The small molecule substances produced by the decomposition of organic matter can increase the adsorption capacity of phosphorus. The saccharides can enhance the adsorption energy of phosphorus (Chen et al. 2015). The amino acids can increase the maximum adsorption capacity of phosphorus. The organic matter and its degradation products can promote the adsorption capacity of sediments on phosphorus in various ways. The content of organic matter was not determined in this study. Considering the relationship between the organic carbon and organic matter, the organic carbon was used in place of organic matter for the analysis in this article. The contents of organic carbon in the sediments from Yangzong Lake were in the range of 0.41\%-6.72\%. The average content of each layer from top to bottom was $3.53 \%, 2.63 \%, 2.21 \%, 2.12 \%$ and $1.91 \%$, respectively. With the increase of depth, the organic carbon decreased gradually. It decreased most significantly at the depth of $0-6 \mathrm{~cm}$ and the decrease of amplitude was slowed down below $6 \mathrm{~cm}$. For the sediments from the depth of $6-10 \mathrm{~cm}$, there was a significant positive correlation between the organic carbon and phosphorus contents (Fig. 6), that is, the content of phosphorus increased with the increase of organic matter.

Human activity: In the sediments from the depth of $0-10 \mathrm{~cm}$, human activity has been a constant factor that affects the phosphorus distribution. The influence degree increases gradually with the enhancement of human activities. The content of phosphorus in the sediments and the variation of spatial distribution both indicated the change of the phosphorous sources (Parsons et al. 2017).

Before the 1980s, the agricultural non-point source pollution and urban sewage discharge were the major sources of phosphorus. Tangchi Town on the north bank and Yangzong Town on the south bank were the areas of intensive human activities and also the main distribution areas of farmland. The phosphorus fertilizer enters the lake with the farmland drainage and storm runoff. The domestic sewage was discharged into the lake through the Baiyi River on the north bank and the Yangzong Lake on the south bank. Therefore, in the sediments from the depth of $6-10 \mathrm{~cm}$, the contents of phosphorus in the area along the shore of Tangchi Town and Yangzong Town were relatively high.

After the 1980s, the industry, mining, tourism and fishery surrounding the Yangzong Lake have emerged. Industrial and domestic sewage discharge has increased. The motor vessels in the lake district increased. The factors such as the cage fish culture in each town along the shore have resulted in an increase of phosphorus discharge into the lake. The water quality of the lake is deteriorating.

The monitoring data in the 1990s showed that the total phosphorus discharged into the lake was about 139.46 tons 
per year. The phosphorus by the cage fish culture was about 72 tons per year, accounting for 52\% of the total amount discharged into the lake. The second largest was the fish culture in pools, and the phosphorus discharged into the lake was about 45 tons per year, accounting for $32 \%$ of the total amount. The third was the industrial wastewater and domestic sewage, with the amounts of phosphorus discharged into the lake being about 6.75 tons per year and 4.38 tons per year, respectively. The amount of phosphorus discharged for non-point source was 11.33 tons per year. The point source pollution is the main form of phosphorus input. The cage fish culture was once distributed along the shore near Tangchi Town and Yangzong Town. Therefore, the phosphorus contents in the sediments from the depth of $2-6 \mathrm{~cm}$ were still high. The phosphorus pollution on the south bank was more serious than that on the north bank. It was because there was a large number of fish culture in pools along the shore to the east of the mouth of Yangzong Lake. The blue-green algae bloomed in the Yangzong Lake for 3 consecutive years from 1997 to 1999 . The water quality decreased to class IV. After that, a series of pollution prevention measures were implemented, such as the banning of cage fish culture and motor fishing vessels in the Tangchi Town on the north bank. One year later, the same measures were also adopted for Yangzong Town on the south bank. The phosphorus content declined significantly after these measures. The water quality gradually recovered to class III. The contents of phosphorus in the sediments on the north and south banks first increased and then decreased from bottom to top (from old to new). This demonstrated that the phosphorus pollution in the Yangzong Lake experienced the transition from light pollution to heavy pollution and then back to light. The decline rate of phosphorus contents in the sediments on the south bank was less than that on the north bank, due to the delayed implementation of the control measures. Besides, the organic carbon in the sediments from the depth of $2-4 \mathrm{~cm}$ had a "significant" correlation with the content of phosphorus. However, the $\mathrm{pH}$ value and ORP for the same layer both had an "insignificant" correlation with the content of phosphorus. We believe that the correlations of natural factors such as $\mathrm{pH}$ value and ORP with phosphorus are weakened due to human interventions (Bertolet et al. 2018). However, the human factor in this period is mainly aquaculture. While the phosphorus is discharged into the lake by the fish farming, a large number of residual feeds producing organic matters and fish excrements are also discharged. Therefore, in the sediments of this layer, the organic carbon had a significant correlation with the phosphorus content.

After 2000, with the increase of the exploitation and development around Yangzong Lake, the soil and water loss arising from land development has become an impor- tant source of phosphorus. The monitoring data in 2005 (Boulion 2018, Welch et al. 2017) showed that the content of phosphorus amounted to 204.4 tons due to the soil and water loss in the Yangzong Lake, accounting for $67.8 \%$ of the total phosphorus discharged into the lake. The second largest pollution is agricultural non-point source pollution. The loss of fertilizer phosphorus was about 51.5 tons, accounting for about $17.1 \%$ of total phosphorus. Point source pollution, such as the industrial wastewater, domestic sewage and aquaculture, also makes a significant contribution. The discharge of phosphorus along with the industrial wastewater was about 40.44 tons; the discharge by the tourism wastewater was 1.11 tons, and that with the urban sewage was 0.224 tons. The aquaculture industry discharged 3.746 tons of phosphorus into the lake. Although the content of phosphorus in the sediments in the local area declined compared with that in the lower layer, the content of phosphorus still showed an increasing trend in the whole lake area. At this time, besides the large number of enterprises rising in the areas along the shores of Tangchi Town and Yangzong Town (such as hot spring resorts, phosphate fertilizer plants and refractory factories), the enterprises such as aluminium factories and golf courses have also developed in Sanshimu and Baojianshan District (Chen et al. 2016, Feng et al. 2019). The phosphorus in the sediments near these areas all presented significant increases.

Since the 1960s, the main source of phosphorus in the Yangzong Lake has changed with time, from the agricultural non-point source to the cage fish farming, and then to soil and water loss. The type of pollution source has changed from the non-point source to point source, and to non-point source pollution. The number of pollution sources is also increasing constantly.

\section{CONCLUSION}

The contents of phosphorus in the sediments from the Yangzong Lake were in the range of $318-3931 \mathrm{mg} / \mathrm{kg}$. The average contents of arsenic in the sediments at the depth of $0-2$, 2-4, 4-6, 6-8 and 8-10cm were 1151, 1126, 1138, 1057 and $893 \mathrm{mg} / \mathrm{kg}$, respectively. Vertically, the content of phosphorus increased gradually from bottom to top. On the planar view, the contents of phosphorus were high on the north and south banks and they decreased towards the centre of the lake. The distribution of phosphorus in the sediments was affected by both the natural factors and human factors. Before the 1980s, the distribution of phosphorus in the sediments was mainly influenced by the natural factors such as the $\mathrm{pH}$ value, redox potential and organic matter. After the 1980s, the distribution of phosphorus was mainly affected by the position of pollution discharge. The phosphorus source in the Yangzong Lake is increasing in number and the pollution type changes 
from the point source to the non-point source pollution. At present, the main sources of phosphorus are soil and water loss and agricultural non-point source pollution. The control of soil and water loss and the loss of chemical fertilizers are crucial for controlling the eutrophication of Yangzong Lake.

\section{ACKNOWLEDGEMENT}

The study was financially supported by projects of the China Geological Survey (No. DD20160308 and No. DD20190331).

\section{REFERENCES}

Bertolet, B.L., Corman, J.R., Casson, N.J., Sebestyen, S.D., Kolka, R.K. and Stanley, E.H. 2018. Influence of soil temperature and moisture on the dissolved carbon, nitrogen, and phosphorus in organic matter entering lake ecosystems. Biogeochemistry, 139(3): 293-305.

Boulion, V.V. 2018. Phosphorus budget of Lake Baikal and the Angara cascade water reservoirs: Modeling, reconstruction, and prognosis. Dokl. Biol. Sci., 480(1): 90-92.

Chen, C.Y., Deng, W.M., Xu, X.M., He, J., Wang, S.R., Jiao, L.X. and Zhang, Y. 2015. Phosphorus adsorption and release characteristics of surface sediments in Dianchi Lake, China. Environ. Earth Sci., 74(5): 3689-3700.

Chen, X., Li, H., Hou, J., Cao, X.Y., Song, C.L. and Zhou, Y.Y. 2016. Sediment-water interaction in phosphorus cycling as affected by trophic states in a Chinese shallow lake (Lake Donghu). Hydrobiologia, 776(1): 19-33.

Feng, W.Y., Li, C.C., Zhang, C., Liu, S.S., Song, F.H., Guo, W.J., He, Z.Q., Li, T.T. and Chen, H.Y. 2019. Characterization of phosphorus in algae from a eutrophic lake by solution 31P nuclear magnetic resonance spectroscopy, Limnology, 20(2): 163-171.

Koskiaho, J., Tattari, S. and Röman, E. 2015. Erratum to: Suspended solids and total phosphorus loads and their spatial differences in a lake-rich river basin as determined by automatic monitoring network. Environ. Monit. Assess., 187: 286.

Li, X.L., Eckhard, G. and Horst, M. 2010. Phosphorus depletion and pH decrease at the root-soil and hyphae-soil interfaces of VA mycorrhizal white clover fertilized with ammonium. New Phytol., 119: 397-404.
Liu, J.Z., Luo, X.X., Zhang, N.M. and Wu, Y.H. 2016. Phosphorus released from sediment of Dianchi Lake and its effect on growth of Microcystis aeruginosa. Environ. Sci. Pollut. Res., 23(16): 16321-16328.

Liu, E.F,, Shen, J., Yang, X.D. and Zhang E.L. 2012, Spatial distribution and human contamination quantification of trace metals and phosphorus in the sediments of Chaohu Lake, a eutrophic shallow lake, China. Environ. Monit. Assess., 184(4): 2105-2118.

Luo, Y.H., Nie, X.Q., Li, X.L., Dai, Z.L., Xu T. and Huang, Y.P. 2017. Distribution and emission flux estimation of phosphorus in the sediment and interstitial water of Xiangxi River. Environ. Sci., 38: 2345-2354. (in Chinese)

Lü, C., He, J. and Wang, B. 2018. Spatial and historical distribution of organic phosphorus driven by environment conditions in lake sediments. J. Environ. Sci., 64: 32-41.

Parsons, C.T., Rezanezhad. F., O'Connell. D.W. and Cappellen, P.V. 2017. Sediment phosphorus speciation and mobility under dynamic redox conditions. Biogeosciences, 14: 1-36.

Peng, J. X. and Chen, H. J. 1987. Eutrophication and Prevention of Water. China Environmental Science Press, pp. 77.

Sieliechi, J.M., Dangwang Dikdim, J.M. and Noumi, G.B. 2014. Speciation of phosphorus in the sediments of Lake Bini (Ngaoundere-Cameroon). Environ. Technol., 35: 1831-1839.

Welch, E.B., Gibbons, H.L., Brattebo, S.K. and Corson-Rikert, H.A. 2017. Distribution of aluminium and phosphorus fractions following alum treatments in a large shallow lake. Lake Reserv. Manage., 33(2): 1-7.

Zhang, Y.X., Liu, J.T. and Wang, J.C. 2013. Distribution of phosphorus in the sediments of Yangzonghai Lake and its influencing factors. Saf. Environ. Eng., 20: 43-48. (in Chinese)

Zhang, Y.X., Sun, J.C., Xiang. X.P., Jing J.H, Liu J.T, Huang G.X., Wang J.C, Chen, Xi and Cui, H.W. 2010. A survey of heavy metals in sediments of Yangzonghai Lake in Yunnan Province: Their source and distribution. Environ. Sci. Technol., 33: 171-175. (in Chinese)

Zhang, Y.X., Xiang, X.P., Zhang, Y., Chen, X., Liu, J.T., Wang, J.C., Zhang, Y.J. and Sun, J.C. 2012. Distribution and sources of arsenic in Yangzonghai Lake, China. Environ. Sci., 33: 3768-3777. (in Chinese)

Zhu, B., Wang, Z.H. and Zhang, X.B. 2012. Phosphorus fractions and release potential of ditch sediments from different land uses in a small catchment of the upper Yangtze River. J. Soil Sediment, 12: 278-290.

Zhu, G.R. and Yang, Y. 2018. Variation laws and release characteristics of phosphorus on surface sediment of Dongting Lake. Environ. Sci. Pollut. R., 25: 12342-12351. 